\title{
BERSIH DESA “KEBOAN” KOMUNITAS USING DESA ALIYAN KECAMATAN ROGOJAMPI KABUPATEN BANYUWANGI
}

\author{
Dwi Ayu Oktavia, Rully Putri Nirmala Puji, Wiwin Hartanto \\ Program Studi Pendidikan Sejarah FKIP Universitas Jember \\ oktaviaayu523@gmail.com,rully@unej.ac.id,wiwinhartanto@unej.ac.id
}

\begin{abstract}
ABSTRAK
Desa Aliyan merupakan salah satu desa tempat basis berkonsentrasinya Suku Using yang ada di Banyuwangi yang masih kental akan adat budaya leluhurnya, yakni salah satu adat budaya leluhur yang tetap dilestarikan adalah Ritul Keboan. Ritual Keboan merupakan budaya bersih desa yang diselenggarakan setahun sekali, khususnya pada Suku Using. Pelaksanaan ritual ini diadakan berkaitan dengan pertanian yang digelar oleh masyarakat Suku Using di Desa Aliyan pada Bulan Sura. Tujuan dari penelitian ini adalah untuk menganalisis ritual adat kebo-keboan sebagai budaya luhur masyarakat Suku Using kabupaten Banyuwangi. Metode penelitian yang digunakan adalah metode penelitian sejarah dengan tahapan: (1) pemilihan topik, (2) pengumpulan sumber, (3) kritik sumber, (4) interpretasi, (5) penulisan sejarah. Hasil penelitian menunjukkan Ritual Adat Keboan merupakan salah satu budaya leluhur Suku Using yang masih dilestarikan oleh generasi Using yang berada di Desa Aliyan, Kecamatan Rogojampi, Kabupaten Banyuwangi.
\end{abstract}

\section{Kata kunci: Ritual, Adat, Keboan, Keagamaan}

\begin{abstract}
Aliyan Village is one of the villages where the base of the Using Tribe is concentrated in Banyuwangi which is still thick with ancestral cultural customs, namely one of the ancestral cultural customs that is still preserved is Ritul Keboan. Keboan ritual is a village clean culture which is held once a year, especially in Using Tribe. The implementation of this ritual was held in connection with agriculture held by the Using Tribe community in Aliyan Village in the Sura Month. The purpose of this study was to analyze traditional ritual kebo-kebo as the noble culture of Suku Using the Banyuwangi district. The research method used is a historical research method with stages: (1) topic selection, (2) source collection, (3) source criticism, (4) interpretation, (5) historical writing. The results showed Keboan Indigenous Ritual is one of the ancestral cultures of the Using Tribe which is still preserved by the generation of Using who are in Aliyan Village, Rogojampi District, Banyuwangi Regency.
\end{abstract}

\section{Keywords: Ritual, Indigenous, Keboan, Religious}




\section{PENDAHULUAN}

Komunitas dan adat-budaya pariwisata berkaitan erat dengan objek wisata sebagai daya tarik pariwisata komunitas suku itu sendiri.

Menurut Aekanu Hariyono, Using adalah salah satu komunitas etnis yang berada di daerah Banyuwangi dan sekitarnya. Dalam ruang lingkup yang luas, Using merupakan salah satu bagian dari sub-etnis Jawa. Sedangkan dalam peta wilayah kebudayaan Jawa, Using merupakan bagian wilayah Saberang Wetan, yang berkembang di daerah ujung Timur Pulau Jawa. Keberadaan komunitas Using berkaitan erat dengan seajarah Kerajaan Blambangan.

Kerajaan Blambangan merupakan salah satu kerajaan yang memiliki sejarah amat menyedihkan, sebab Blambangan terbelenggu oleh pendudukan dan penjajahan pihak luar, diantaranya Majapahit, Demak, Mataram, Pasuruan, Buleleng, dan Belanda. Tahun 1765 saat melawan penjajah Belanda, kurang lebih 600.000 rakyat Blambangan terbunuh untuk mempertahankan wilayahnya. Menurut Andrew Beatty (2003) diduga etnis Using ini merupakan sisa penduduk tahun 1768 atau sisa dari rakyat Blambangan.

Penamaan Using ini diberikan oleh penduduk imigran, yakni orang Jawa Kulon yang datang ke tanah Banyuwangi bersamaan dengan dibukanya perkebunan oleh pihak penjajah Belanda pada abad 18 dan 19. Penduduk asli Banyuwangi tidak mau hidup bersama dengan wong kulonan sehingga oleh para imigran menyebut mereka Using, yang mana "sing" berarti tidak atau bukan. $\quad$ Orang kulonan menambahkan $u$ guna menegaskan dan menamai rakyat Blambangan sebagai rakyat yang lebih dahulu mendiami wilayah Jawa pucuk Wetan ini (Anoegrajekti, 2015: 5859).

Masyarakat Using Banyuwangi berpusat di kecamatan Glagah, Singojuruh, Kabat, Giri, Rogojampi, Songgon, 
Banyuwangi Kota, Cluring, dalam penelitian ini berdasarkan Genteng, dan Srono. Dan tersebar di kedekatan emosional dan beberapa desa diantaranya Desa kedekatan intelektual. Dalam Kemiren, Aliyan, Alasmalang, kedekatan emosional dikarenakan Olehsari (Anoegrajekti, 2015: 61). Setiap upacara yang dilakukan oleh masyarakat Using berbeda dan memiliki sesuatu yang unik dalam budaya di masing-masing tempat (Salamun, dkk, 2015: 3).

Penelitian ini bertujuan untuk memahami tentang Budaya Keboan sebagai warisan leluhur Suku Using yang ada di Desa Aliyan, Kecamatan Rogojampi, Kabupaten Banyuwangi.

\section{METODE}

Peneliti menggunakan metode sejarah. Menurut Kuntowijoyo dalam Pengantar Ilmu Sejarah (2013) ada lima tahapan penelitian sejarah. Kelima tahapan penelitian sejarah diatas dapat diuraikan sebagai berikut.

\section{Pemilihan Topik}

Pemilihan topik ini seringkali jadi kendala bagi peneliti karena tidak sedikit para peneliti bingung dengan apa yang akan mereka bahas. Pemilihan topik peneliti tinggal di Kabupaten Banyuwangi selama sembilan belas tahun, dan selama itu peneliti seringkali mendengar ritual adat keboan. Sedangkan dalam kedekatan intelektual dilatarbelakangi oleh mata kuliah Sejarah Kebudayaan, Sejarah Lisan, dan Sejarah Indonesia yang ada di Program Studi Pendidikan Sejarah, Fakultas Keguruan dan Ilmu Pendidikan, Universitas Negeri Jember. Setelah itu peneliti kemudian menyusun rencana penelitiannya.

\section{Heuristik}

Pengumpulan sumber (heuristik) berupa dokumen atau literatur buku dalam penelitian ini diperoleh dari perpustakaan yang memiliki korelasi dengan judul yang dibahas oleh peneliti. Selain itu juga untuk memperoleh sumber yang lebih valid, peneliti melakukan observasi ke lapangan dengan melakukan wawancara 
terhadap informan-informan yang diasumsikan dapat memberikan data yang diperlukan oleh peneliti

\section{Verifikasi (Kritik Sumber)}

Kritik sumber sejarah dalam penelitian ini menggunakan kritik ekstern (autentisitas) dan kritik intern (kredibilitas). Kritik ekstern digunakan untuk melihat keaslian dari sumber yang diperoleh dari segi fisiknya. Sedangkan kritik intern digunakan untuk mengecek isi dari sumber yang diperoleh, apakah sumber tersebut valid atau tidak untuk digunakan.

\section{Interpretasi (Penafsiran)}

Data atau fakta sejarah yang telah diperoleh pada tahap verifikasi merupakan bukti dari peristiwa sejarah. Pada tahap interpretasi ini data atau fakta sejarah yang telah diperoleh di analisis dan di sintesis. Fakta-fakta sejarah yang telah diperoleh dicari korelasinya dan kemudian dijadikan sebagai satu kesatuan yang utuh. Pada tahap ini juga data atau fakta yang telah diperoleh di pilah antara yang dibutuhkan dan membuang yang tidak dibutuhkan.

\section{Historiografi (Penulisan)}

Pada tahap penulisan sejarah atau historiografi faktafakta sejarah yang telah di interpretasi di tulis secara kronologis sesuai dengan data yang telah diperoleh. Penyajian tulisan sejarah terdiri atas pendahuluan, pembahasan, dan simpulan.

\section{HASIL DAN PEMBAHASAN}

Desa Aliyan, Kecamatan Rogojampi, Kabupaten Banyuwangi, Jawa Timur, terdiri dari 18 desa dan 7 dusun yang meliputi Dusun Krajan, Sukodono, Kedawung, Cempokosari, Danurejo, Timurejo, dan Dusun Bolot.

Nama Desa Aliyan memiliki sejarah yang cukup menarik, sebelumnya desa ini bernama Desa Karangmukti. Penduduk Desa Aliyan pada mulanya adalah pendatang dari Desa Mangir. Mereka memilih menetap di Desa Aliyan karena melihat tanahnya datar dan rata serta air yang tersedia cukup banyak

Nama Desa Aliyan diambil dari corak kehidupan masyarakat 
pada waktu itu. Pada saat itu masyarakat sering berpindahpindah dari suatu tempat ke tempat lain. Desa Aliyan berasal dari kata "alih" yang kemudian mendapat akhiran -an. Dalam bahasa Indonesia, "ngalih" berarti pindah, sedangkan dalam bahasa Using menjadi ngalihan yang kemudian mengalami perubahan sebutan menjadi Aliyan.

Di Desa Aliyan ada dua upacara berkaitan dengan pertanian, yaitu upacara yang disebut keboan dan kumara. Upacara keboan sampai sekarang masih diselenggarakan warga setiap bulan Sura, sedangkan upacara kumara sudah ditinggalkan.

Ritual keboan di Desa Aliyan ini diselenggarakan di dua dusun, yaitu Dusun Aliyan dan Dusun Sukodono. Meskipun ritual ini diselenggarakan dengan prosesi dan pada hari yang sama akan tetapi acara ritual ini tidak bisa diselenggarakan secara bersamaan. Hal ini dikarenakan apabila ritual keboan dua dusun ini bertemu, maka mereka akan saling serang, sebab roh ghoib yang merasuki tubuh pelaku keboan beda asalnya atau tidak sama. Sehingga dalam pelaksanaannya waktu dan jalur prosesi idher bumi dibedakan.

$$
\text { Upacara Keboan di }
$$

Banyuwangi berkembang di dua desa, yaitu Desa Aliyan Kecamatan Rogojampi (keboan), dan Desa Alasmalang Kecamatan Singojuruh (kebo-keboan). Kedua ritual desa ini hampir sama dalam pelaksanaannya, yaitu diawali dengan prosesi arak-arakan manusia atau yang disebut dengan idher bumi. Dan selain itu juga memiliki tujuan yang sama, yaitu menolak balak dan bentuk rasa syukur masyarakat terhadap Yang Maha Kuasa atas hasil panen yang melimpah.

Sehari sebelum upacara adat keboan dilaksanakan, masyarakat Desa Aliyan mempersiapkan segala sesuatu untuk ritual ini, yaitu: masyarakat menyiapkan dan memasang umbul-umbul (bendera berwarnawarni) di sepanjang jalan desa, 
membuat gapura yang dibuat dari bambu yang dipasang di pintupintu jalan masuk Desa Aliyan. Gapura ini disebut lawang kori, ada yang menyebut pura kencana atau pura bungkil.

Selain itu masyarakat membuat kubangan atau guyangan. Dan juga warga membuat gunungan hasil bumi atau hasil panen. Yang merupakan simbol keberhasilan petani dalam bercocok tanam.

Dalam pelaksanaanya, upacara atau ritual keboan ini diawali dengan diselenggarakannya acara selamatan desa tepatnya di empat penjuru desa yang kemudian dilanjutkan dengan prosesi idher bumi. Dalam prosesi idher bumi inilah para pelaku keboan melakukan ritual seperti halnya siklus bercocok tanam, dari membajak sawah, mengairi, hingga menabur benih.

Para pelaku keboan ini diperankan bukan kerbau atau sapi asli, melainkan manusia yang telah dipilih oleh roh leluhur. Pada waktu pelaksanaan ritual ini para pelaku keboan dirias menyerupai seekor kerbau yang dilumuri oleh cairan hitam legam terbuat dari oli dan arang yang lengkap dengan menggunakan tanduk lancip dan kalung sapi.

Para pelaku keboan dirasuki oleh roh ghoib atau roh nenek moyang, sehingga mereka dalam ritual ini tidak sadar dan terpaksa diikat dengan tali agar tidak membahayakan pengunjung yang menonton. Dalam ritual ini para pelaku keboan bertindak layaknya seekor kerbau, mereka berkubang dan bergulung-gulung di lumpur sawah yang sudah disiapkan.

Keboan sudah menjadi bagian dari kehidupan masyarakat Banyuwangi, khusunya Suku Using. Sehingga hewan kerbau disimbolkan sebagai mitra petani dalam menggarap sawah dan berupaya mendapatkan hasil panen yang memuaskan serta mencapai kemakmuran.

\section{PENUTUP}

Ritus slametan Keboan merupakan ritual yang dilaksanakan setiap tahunnya di 
bulan Sura. Ritual ini merupakan budaya sedekah desa atau bersih desa yang dilakukan oleh Suku Using sebagai rasa ucap syukur kepada Yang Maha Kuasa.

Sebelum melaksanakan ritual ini masyarakat menyiapkan segala sarana dan prasarana yang menunjang jalannya ritual ini. Tepatnya sehari sebelum kegiatan ini berlangsung masyarakat menyiapkan dan memasang umbul-umbul, membuat gapura yang dibuat dari bambu, membuat kubangan atau guyangan, membuat gunungan hasil bumi, menyiapakan sesaji, menyiapkan singkal/bajak. Dan pada malam hari sebelum ritaul ini dimulai, para sesepuh desa berkumpul untuk memusyawarahkan siapa yang akan menjadi tokoh dan pelaku keboan atau menusia kebo.

Pada pagi harinya, masyarakat mengadakan selametan dan dilanjutkan dengan arak-rakan manusia keliling desa atau idher bumi. Para pelaku keboan mengelilingi desa. Ketika melakukan idher bumi, para pelaku keboan sudah banyak yang mengalami kesurupan atau tidak sadar. Dan diakhiri dengan pelaku keboan menggarap sawah hingga menabur benih.

\section{DAFTAR PUSTAKA}

Anoegrajekti, N. 2009. Satra dan Budaya Lokal Masyarakat Using: Diktat. Jember: Fak. Sastra-Universitas Jember.

Anoegrajekti, $\quad$ N., dkk. 2016. Kebudayaan Using:

Konstruksi, Identitas, dan Pengembangannya.

Yogyakarta: Ombak.

Beatty, A. Variasi Agama di Jawa: Suatu Pendekatan Antropologi. Terjemahkan oleh Syaefuddin, Akhmad Fedyani. 2001. Jakarta: PT. Raja Grafindo Persada.

Kuntowijoyo. 2013. Pengantar Ilmu Sejarah. Yogyakarta: Tiara Wacana.

Salamun, dkk. 2015. Komunitas Adat Using Desa Aliyan Rogojampi Banyuwangi Jawa Timur: Kajian Ritual Keboan. Yogyakarta: Balai Pelestarian Nilai Budaya.

Sumarsono, dkk. 2009 . Nilai-Nilai Kemasyarakatan pada Masyarakat Using di Banyuwangi. Yogyakarta: Kencana

Syaiful, M., dkk. 2015. Jagat Osing (Seni, Tradisi \& Kearifan Lokal Osing). Kementrian 
Pendidikan dan Kebudayaan Republik Indonesia.

Tim Penelitian Lapangan Antropologi. 2004. Menyibak Ranah Using Sebuah Catatan Etnografis Masyarakat Using. Jember: UNEJ Press. 